\title{
Discurso de Posse do Professor Geraldo Ataliba*
}

Excelentíssimo Senhor Diretor; Egrégia Congregação, Senhor Secretário da Justiça, José Carlos Dias; Senhor Secretário da Segurança Michel Temer; Senhor Presidente da Ordem dos Advogados do Brasil, Mário Sérgio Duarte Garcia; Senhor Presidente da Ordem dos Advogados, Seccional de S. Paulo, Márcio Tomás Bastos; Senhores Desembargadores, Procuradores da República, da Justiça, do Estado, do Município; Senhores magistrados. Colegas professores, advogados, Senhores alunos; Senhoras e Senhores.

É provecto o asserto de que ninguém vai para o céu, ou para o inferno, sozinho. Somos levados e, ao mesmo tempo, ajudamos a conduzir, aos que nos cercam. O asserto vale para a vida, para todos os episódios da nossa vida.

Após longa caminhada, aqui chego, trazido por uma multidão de pessoas, que de modo mais ou menos intenso, para isso influiu. A elas, portanto, o meu principal pensamento, de gratidão.

O velho professor ATALIBA NOGUEIRA - cuja jovial presença foi constante nesta escola durante 35 anos - foi o animador de minha vocação, não só genericamente pelo direito, mas especificamente pelo direito público, sobre cuja importância soube eficazmente despertar o interesse do jovem estudante. Com ele aprendí a não ter preconceitos e a abominar todo extremismo.

Nele admirei a firmeza de caráter e a doçura com que enfrentava as adversidades, sem quebra de seu formidável ânimo de luta. Mas, onde o jurista, o cidadão, o advogado, o professor e o pai se fundiam era no traço que melhor define sua personalidade, de todos os aqui presentes fartamente conhecida: ATALIBA NOGUEIRA sabia compreender quem o adversava, detinha-se sempre na busca das razões, objetivas ou subjetivas, dos que alguma vez o antagonizaram. Com isso, pacificava seu ânimo, aplacava seus ímpetos e superava suas divergências. Dele ficaram para sempre, neste salão nobre, nesta casa e na memória de todos nós a imagem do professor jovial, alegre e contagiantemente otimista, que, de um modo ou outro, marcou nossa vida.

Quem melhor e mais sinteticamente o retratou - sem que seu transparente afeto lhe toldasse o julgamento - foi o Prof. Celso

\footnotetext{
* Professor das Faculdades de Direito da Universidade de São Paulo e da Pontifícia Universidade Católica de São Paulo.
} 


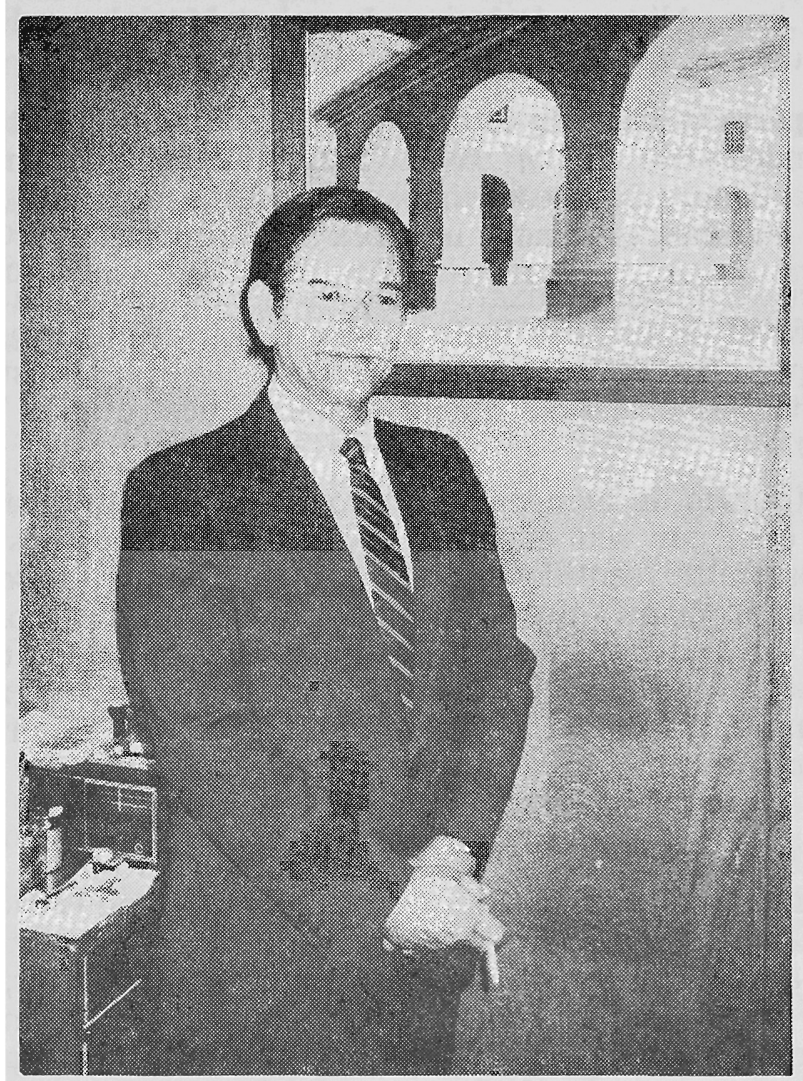

Professor Doutor Geraldo Ataliba. 
Antônio Bandeira de Mello, que escreveu: «Exigente na limpidez e ortodoxia das teses, era contudo, por sua profunda humanidade, condescendente no caso concreto, dada sua natural bondade e compreensão do ser humano».

Das preciosas riquezas que dele herdei e que cultivo com dedicada veneração, saliento a amizade pelos mestres desta casa, de sua geração, a quem homenageio na pessoa dos queridos professores Philomeno Joaquim da Costa, Celso Neves e Canuto Mendes de Almeida; herdei também a estreita amizade de Lourival Vilanova, Ruy Cirne Lima, Aliomar Baleeiro, Josaphat Marinho e Raul Machado Horta, que cultivo com o mais venerando carinho.

Fui despertado para os estudos de Filosofia do Direito por Celso Antônio Bandeira de Mello, amigo fiel, que comigo caminha desde 11 anos de idade. Sem este indispensável lastro, não poderia ter alcançado a mínima coerência na obra que produzi.

Solidifica-se minha paixão pelo Direito Público na leitura da obra insuperável de um dos mais sólidos constitucionalistas da atualidade, o sempre atual SEABRA FAGUNDES, de quem, posteriormente, - há 15 anos - tornei-me amigo próximo, desfrutando o privilégio de seu afeto.

Especial preito de homenagem devo render a dois ilustres mestres desta casa, que, por seu exemplo, espírito científico, postura acadêmica e desassombro sentido do tempo que vivemos - sensiveis que sempre foram ao clamor dos injustiçados, dos indefesos, dos despossuídos - sem vacilações, pautaram seu comportamento por uma intransigente linha de independência de pensamento e paradigmática censura à acomodação, à indiferença, à omissão, que desgraçadamente comprometem nossas elites com o pior do nosso passado, condenando a sociedade, como um todo, a um amargo futuro.

José Ignácio Botelho de Mesquita e Fábio Konder Comparato, juristas exemplares e cidadãos presentes, com intensidade, ao momento que a nação vive. Ao prof. José Ignácio - que, na sua posse, nos exorta a meditarmos sobre nossas responsabilidades, perante a sociedade, à luz dos fins desta escola, os quais só podem ser alcançados pela constante meditação, de todos nós, professores e alunos, em torno de seus perenes ideais - a ele digo agora: não foi vã sua pregação; são muitos os que, como Vossa Excelência, crêem que a Faculdade de Direito da Universidade de São Paulo não é e não pode ser mero centro de instrução para formação técnica de peritos em lidar com leis. E pelo contrário uma instituição da sociedade, onde a ciência do Direito é trabalhada, estudada, criticada, aprofundada e cultivada, como instrumento da justiça.

Ao Professor Fábio Comparato - que ingressando na Congregação formulou grave declaração de princípios e solene juramento de pugnar contra o «servilismo jurídico, pávido e degradante» - oferego como minha pessoal e modesta resposta os meus trabalhos, em que 
procurei realizar, como homem do direito, a proposta que nos é comum. Reitero, repito e faço meu o seu juramento, na convicção de que todos nós juristas, ou nos fazemos sacerdotes do direito, ou servimos mercantilisticamente a qualquer conveniência de ocasião.

Quando há dezesseis anos escrevi um livro sobre decreto-lei, censurando o próprio instituto e os abusos e arbitrariedades que ensejava, fui chamado de ingênuo. Pouco depois, quando no livro sobre lei complementar, denunciei o disparate de se pretender, com seu uso, flexibilizar a Constituição - desrespeitando-se a tábua de direitos fundamentais do homem, a triparticipação do poder, a federação e a autonomia municipal - fui considerado «quixote».

Quando escrevi sobre a faculdade regulamentar mostrando que a maioria dos regulamentos vigentes são inconstitucionais, por invasão da esfera legislativa, ou outras violações, fui tido por cândido. Quando, em todos meus trabalhos, escritos ou orais preguei - sem concessões ao oportunismo ou à acomodação - a supremacia constitucional contra o arbítrio dos poderes constituídos - especialmente do executivo - fui acoimado de poeta.

Quando insisti, reiterei e repeti que os princípios jurídicos (porque encerram as diretrizes estimativas do sistema) sobrepõem-se às simples regras - mesmo quando emanadas do mais poderoso «GENERAL DO DIA» - fui tachado, ironicamente, de espadachim.

Professor Fábio Konder Comparato. Meus escritos, as conferências, aulas, palestras e outros pronunciamentos, ao longo de vinte anos, são expressão de minha concepção do direito como instrumento do homem e da sociedade, para realização de valores, individuais e sociais, harmonicamente. Ouso pensar que, no limite de minhas possibilidades, venho correspondendo à sua convocação e ao magnífico exemplo que vossa excelência e o professor José Ignácio Botelho de Mesquita me vêm dando, desde nossa convivência no curso secundário.

A Dalmo Dallari devo - devemos todos nós - particular apreço por seu desassombrado e corajoso desprendimento, no pugnar, do alto de sua autorizada cátedra, pelos direitos fundamentais do homem. Sua autoridade moral e jurídica só engrandece esta faculdade.

Não posso, nesta altura, deixar de consignar um crédito de gratidão particular a meu mestre de direito tributário, amigo leal, altivo cientista e professor por excelência, Antonio Roberto Sampaio Dória, cujo apoio, exemplo e incentivo foram tão importantes no decurso de minha vida acadêmica. E-me honroso e profundamente grato, sentar-me ao seu lado, como seu colega.

A duas mulheres devo, de modo muito particular, as condições que me permitiram responder aos estímulos, incentivos e ajuda que de tantos recebi: minha mãe, Alexandra, e minha mulher, Anna Maria, cujas qualidades de doçura, compreensão e carinho cercaram cada qual a seu modo - minha vida, que, graças a elas, chega a este momento culminante. 


\section{Senhores Professores,}

Ao receber das ilustres mãos do ínclito internacionalista professor Vicente Marotta Rangel, Diretor desta casa, diante da douta Congregação, esta grave investidura - marcada por responsabilidades, mais que por glórias - permito-me expressar convicção arraigada, que em mim brotou já no início dos meus vinte anos de exercício das honrosas atribuições de livre docente e que se foi robustecendo ao longo de minha intensa atividade. Creio já ser tempo de pensar-se em alargar o órgão máximo dirigente desta casa à participação dos professores que, já livres-docentes, exercem encargos letivos - nossa principal missão universitária: a transmissão do conhecimento, o treinamento no estudo da ciência do Direito -, da mesma forma que os titulares.

Justo, correto, saudável, estimulante e enriquecedor para a instituição, assim, que esses comprovadamente valiosos colegas tenham maior e mais intensa participação também nas responsabilidades decisórias.

Ao expressar estes conceitos não pretendo senão dar uma contribuição ao aprimoramento das condições de funcionamento da escola. De todo modo - senhor Diretor e Egrégia Congregação - permito-me a satisfação de partilhar a honra, a alegria, as glórias deste momento com todos os colegas livres-docentes da Academia de São Francisco.

\section{Egrégia Congregação,}

Minhas intensas atividades de professor - ininterruptamente desenvolvidas nestes vinte anos, fecundadas pelo exercício da advocacia - foram-me robustecendo na convicção da imperiosa necessidade de uma revisão no currículo de formação do bacharel, até como causa e efeito de uma já seródia resposta à realidade da vida atual.

Refiro-me à evolução da sociedade, que - a despeito de qualquer teoria ou ideologia - provoca a publicação de quase todo o direito positivo, seja pela ampliação da ação do estado em todos os setores, seja pela necessidade da preservação dos interesses coletivos, a permear quase todas as relações sociais.

Impõe-se, instantemente, redimensionar os esquemas de preparação dos profissionais do direito, para melhor habilitá-los a servirem à sociedade e aos seus integrantes, pelo estudo o mais intenso do direito público, especialmente por seus grandes princípios e diretrizes, mais do que por suas formas da apresentação empírica.

Não somos realistas, na medida do impostergavelmente necessário, se não reconhecermos a necessidade de aumentar a carga horária dos estudos de filosofia do direito, teoria geral do direito, direito constitucional e direito administrativo. A formação básica que tais estudos infundem será universalmente útil. Para ampliá-la, basta considerar 
- como a experiência o demonstra - que a coisa mais prática que há é uma boa teoria.

Não viveríamos um tão aflitivo subdesenvolvimento cultural com graves reflexos no clima institucional e na própria vida econômica se soubessemos valorizar mais amplamente e com mais profundidade os princípios informadores da República, da Federação, da Autonomia Municipal, da tripartição do poder, da legalidade, da igualdade e do respeito aos direitos da pessoa humana; do constitucionalismo, em uma só palavra. Da teoria jurídica civilizada e culta, que quanto mais conhecida será mais estimada; quanto mais praticada, melhor será vivida e aprimorada. A ordem, a prosperidade, a segurança, a paz virão por acréscimo - ao contrário do que pregam os arautos dos extremismos.

Amor às instituições republicanas, que asseguram a alternância no poder e a responsabilidade política dos governantes, representantes do povo - titular da coisa pública; estima pela federação, como expressão de sadia e democrática descentralização política; apreço à autonomia municipal, como afirmação republicana de uma das mais tradicionais e elementares liberdades públicas, traduzida na afirmação do princípio do auto-governo, no plano da sociedade menor, mais autêntica e mais lídima, a dos vizinhos - no cuidado dos seus assuntos comuns - que a sabedoria política dos constituintes de 1981 designou por «peculiar interesse local».

Apego à tripartição do poder, como única fórmula realista e eficaz de contenção dos excessos, do arbítrio e das tentações da tirania; fé na legalidade, como garantia da imparcialidade da ação estatal e das liberdades fundamentais de todos e cada um; devoção à igualdade, como penhor da proteção das minorias e segurança do direito de dissentir, criticar e adversar os poderosos, políticos ou econômicos. Por fim, entranhado amor aos direitos humanos, como sinal de civilização, espírito cristão e elevação moral, sem o que nenhuma sociedade pode merecer a estima de seus integrantes. Direitos humanos - internacionalista prof. Marotta Rangel - acima de tudo, a todo custo e a despeito de todas as incompreensões egoísticas. Porque só o egoísmo materialista inspira os seus adversários, na argumentação tendente a postergá-los ou esvaziá-los — sabem-no bem os ex-presidentes da Comissão de Justiça e Paz, o Prof. Dalmo Dallari e o Secretário José Carlos Dias, batalhadores desassombrados dessa causa.

Não há conveniência, ideologia ou circunstância que possa justificar a sua violação. Quando uma sociedade cede nesse ponto ainda que em medida mínima - está solapando a pedra de toque de todo princípio social; caminha - pela ausência de valores - para a absoluta derrocada dos critérios morais que fundam a própria noção de convivência social. Como no nazismo e no fascismo, destroi-se a si mesma. 
Só tenho um comportamento exemplar, que infunda nos terceiros a certeza de nossa convicção, os profissionais do direito teremos oportunidade de imprimir seus valores na sociedade e incutir os princípios jurídicos nos seus membros, governantes e governados.

Só agindo com dignidade sacerdotal - própria de quem tem profunda fé nos objetivos a que serve - faremos do direito eficaz instrumento de justiça, para o que é condição indispensável que os terceiros, leigos, nele também acreditem o que somente será possível se tiverem confiança nos seus agentes. Basta esta consideração para mostrar que o problema da formação do bacharel não é meramente técnico, mas também ético, como sempre timbrou em salientar o saudoso desembargador Bandeíra de Mello, meu mestre e amigo.

$\mathrm{E}$ imperioso que se dissipe a imagem corrente do advogado enganador, bem falante, vazio e inconseqüente, que - a pretexto de servir a todos - termina servindo a tudo.

$\mathrm{E}$ instante a necessidade de restaurar-se o prestígio das profissões jurídicas, não por nossa comodidade (de seus executores), mas como condição de podermos servir à sociedade e aos carentes de justiça, com a dignidade e o decoro que os valores do direito exigem.

$\dot{E}$ decisivamente importante resgatar a dignidade da retórica jurídica, como meio de convencimento das pessoas e, pois, instrumento de modificações sociais e individuais.

Nossa arma é a retórica, fundamental ao modo dialético e questionante - próprio, típico dos parlamentos - de elaboração das leis; aos procedimentos de interpretação, maiêuticos e dialogais; ao processo de aplicação jurisdicional, eminentemente contraditório.

A transformação gradativa, paulatina, lenta e penosa da sociedade, há de supor ingente, empenhado, exaustivo uso da palavra. «Somos todos - disse Fábio Comparato - homens da palavra; e disso devemos nos orgulhar».

Será a pregação constante - e jamais a violência silenciosa que se traduzirá em atos construindo, reconstruindo, aprimorando os homens e a sociedade. A palavra antecede à ação. "No princípio era o verbo». Foi a pregação da democracia, da igualdade, da justiça que trouxe o constitucionalismo ao mundo ocidental; foi a pregação dos pais da pátria que trouxe a independência; foi a pregação libertária e constante dos propagandistas políticos que nos deu a república; a palavra comove, impele, modifica, cala. $\hat{E}$ mais fecunda, mais eficaz e mais forte que todas as violências.

$\hat{E}$ preciso, assim, dar autoridade e responsabilidade a quem dela faz uso responsável, como o jurista. É preciso dar substância, coerência, seriedade, elevação ao discurso jurídico, escrito ou oral. Só assim o direito terá a eficácia que dele todos esperamos, para o bem da sociedade. São lições perenes de Goffredo Telles Jr. e Tércio Sampaio Ferraz. 
Ora, isso somente será possível quando, nos cursos jurídicos, se ensinar mais a meditação sobre os alicerces, as bases, os valores, as diretrizes; numa palavra: os princípios que dão sentido ao sistema jurídico e sem os quais este é mero instrumento de arbítrio ou de proveitos classistas ou pessoais.

O direito não é - não podemos consentí-lo, por nosso comportamento e nosso discurso - um amontoado caótico de regras, que pode ser acrescido de qualquer modo, e do qual cada um pinça ou retira - de acordo com sua comodidade ou conveniência - o enunciado que lhe apetece, relegando o que lhe contraria.

Insta que ensinemos aos nossos alunos - com insistência, até a exaustão - que o direito é uno e sistemático e que todas as normas que o formam são harmônicas entre si, dotando-o (ao sistema) de coerência interna.

Esta unidade e sistematicidade se constroem - assim o vê o jurista - em função dos princípios, que funcionam como pedras angulares ou alicerces do sistema. Os princípios encerram - mais do que as regras - as diretrizes estimativas do direito positivo, objeto do nosso estudo. E os valores assim consagrados, à sua vez, organizam-se hierárquica e sistematicamente em função de sua amplitude e abrangência.

A fidelidade da norma aos valores, a submissão dos atos de aplicação às normas é que dão a garantia da segurança jurídica, a certeza da igualdade, a previsibilidade dos comportamentos institucionais, a paz, o clima para o trabalho, a harmonia social; a liberdade, enfim, supremo valor humano, a maior promessa constitucional, que cabe ao Judiciário tornar eficaz, com a nossa imprecindivel colaboração.

Esta é a nossa fé. Que Deus nos ajude a traduzí-la em realidade.

\section{SAUDAÇÃO AO PROFESSOR GERALDO ATALIBA}

Há quarenta e quatro anos, exatamente em 12 de outubro de 1940, tomava posse neste mesmo recinto, como Professor Catedrático de Direito Público e Constitucional, disciplina logo desdobrada em Teoria Geral do Estado e Direito Constitucional, o Professor José Carlos de Ataliba Nogueira.

Quase meio século após, quando seu filho repete, no mesmo cerimonial, o ato simbólico de ingresso à douta Congregação, imaginamos com dificuldade o ambiente daquela época, no Brasil e no mundo.

A invasão da Polônia pela Wehrmacht, na madrugada de $1^{\circ}$ de setembro de 1939, precipitava o ocaso definitivo da civilização européia, na qual se haviam criado os homens daquela geração. No plano da economia mundial, a fúria bélica mal disfarçava a decadência, provocada pela exaustão dos pactos coloniais e o fracionamento do 
mercado comum europeu em unidades autárquicas, fanaticamente nacionalistas. No prélio das idéias políticas, o duelo entre nazi-fascismo e social-comunismo parecia enterrar para sempre, na vala comum dos regimes ultrapassados, a idéia democrática de Estado de Direito, supremacia da vontade popular majoritária e proteção aos direitos individuais. No nível mais profundo da consciência coletiva, uma nova crise, em tudo antitética à que havia gerado a mentalidade moderna em fins do século XVII, despontava nos centros culturais do Ocidente: com exceção dos marxistas e dos cristãos, os intelectuais pompeavam o irracionalismo e proclamavam as virtudes do desespero lúcido.

Tais sucessos, como sintomas agudos da crise do organismo mundial, no sentido hipocrático do termo, - o momento preciso em que o estado do paciente enseja o diagnóstico e o prognóstico - não deixaram de atingir decisivamente o nosso país. No plano político, o autoritarismo estatal, apoiado pela força militar, conquistava adeptos até mesmo entre os antigos e futuros liberais. Do totalitarismo europeu, cuja perfeição hitlerista e stalinista éramos incapazes de alcançar, tomamos o aspecto massificante e mistificante da política populista. No terreno econômico, como conseqüência da grande depressão dos anos 30 e mais agudamente em razão da guerra, conhecemos o segundo surto de industrialização do século, dando início a fundas transformações sociais. No plano cultural, enfim, a crise européia suscitou um dos mais fecundos movimentos de idéias jamais registrados em nossa história: a investigação sobre o caráter nacional brasileiro. «Macunaíma» irrompe em 1928; «Raízes do Brasil», de Sérgio Buarque de Hollanda, é publicado em 1936; «Formação do Brasil Contemporâneo», de Caio Prado Jr., em 1942.

À época, a Faculdade de Direito de São Paulo gozava de imenso prestígio. Ingressar em sua congregação correspondia à meta final de todo um programa de vida, o coroamento de um cursus honorum.

Ém 1984, data simbólica para muitos intelectuais da geração do Professor José Carlos de Ataliba Nogueira, o mundo oferece um espetáculo muito diverso, não só da época em que ele assume a cátedra nesta Casa - o que era facilmente previsível - , mas também do quadro futurista imaginado por George Orwell e outros, num exercício de ficção premonitória que chegou a encantar alguns bons espíritos.

Por trás do espetáculo aparatoso da bipolaridade na hegemonia mundial, levanta-se uma realidade mais profunda e decisiva: a dissociação crescente entre a humanidade desenvolvida e a subdesenvolvida, numa cisão histórica aparentemente irreversível, inconcebida há meio século. Além disso, fato inédito na História, o anunciado advento da civilização mundial coincide, curiosamente, com o declínio das ideologias de vocação mundial. Entramos no tempo do mundo acabado, nâo propriamente de costas como dizia Paul Valéry, mas às escuras e sem ânimo. O Professor Ataliba Nogueira, admirando 
o passado, pregava ardorosamente o ressurgimento de velhás tradições, cristãs e políticas, como o único remédio eficaz contra a morbidez de sua época. Manifestava, com isto, um dos aspectos mais interessantes de sua personalidade de alegre contemptor das idéias da moda. Num momento em que todas as doutrinas políticas acabavam redundando numa Allgemeine Staatslehre, ele reduzia o Estado a mero instrumento, mutável e contingente, da realização do bem comum. Quando o liberalismo morno e dobre requentava idéias de Beccaria e Montesquieu sobre crimes e penas, antes de resvalar para o Tribunal de Segurança e a Polícia Especial do Estado Novo, o Professor Ataliba Nogueira ousava propor a pena sem prisão e o estabelecimento de medidas de segurança. Nos tempos em que a grande finesse intelectual consistia em afetar o mais acadêmico agnosticismo, ele exibia uma religiosidade estrepitosa e tradicionalista.

Hoje, porém, o retorno aos valores tradicionais perdeu todas as virtudes críticas, que o tornavam um útil elemento de corrosão das falsidades oficiais. Todos sabem, mais ou menos conscientemente, que os principais problemas do presente não encontram antecedente histórico e não podem ser compreendidos à luz da experiência. Mais do que nunca, a sobrevivência humana depende da capacidade inventiva.

Em nosso país, 1984 é literalmente outra época histórica em relação a 1940. A fisionomia sócio-econômica da população se apresenta, de certa forma, invertida, entre essas duas datas. Em 1940, os trabalhadores do setor primário da economia representavam dois terços da população economicamente ativa; hoje, não chegam a $30 \%$. Entre campo e cidade, a inversão da repartição populacional é quase matematicamente exata: em 1940, a população urbana representava $31,2 \%$ da população total e a rural $68,8 \%$; pelo censo de 1980 , os urbanos são $67,5 \%$ e os rurais $32,5 \%$.

Ademais, a relação Estado - sociedade civil exibe mudanças significativas. Pela primeira vez em nossa história, surgem movimentos sindicais, urbanos e rurais, não controlados pelo Poder Público nem bitolados por preconceitos ideológicos. Multiplicam-se as comunidades de base e as associações de bairro, num movimento instintivo de auto-defesa em todos os quadrantes. Parece óbvio, a qualquer observador lúcido, que a urgente necessidade de uma recomposição do Estado brasileiro, desconjuntado pela criminosa aventura da segurança nacional, não poderá ser empreendida com êxito nos moldes tradicionais, sob a forma de um arreglo entre chefes políticos, ou entre estes e a corporação militar, sem a participação direta do povo.

$E$ nesse contexto histórico, fascinante sob tantos aspectos, Senhor Professor Geraldo Ataliba, que V. Exa. toma posse como Professor Titular nas Arcadas. Seu labor doutrinário concentrou-se no direito público, sobressaindo o pendor pela discussão das questões jurídico-tributárias à luz dos princípios constitucionais. Ã experiência de duas décadas de ensino superior, V. Exa. acrescenta ainda à da mais 
alta direção universitária, como Reitor que foi da Pontifícia Universidade Católica de São Paulo.

Seu ingresso no Departamento de Filosofia e Teoria Geral do Direito há de ser a ocasião propícia para que V. Exa. venha prestar sua valiosa colaboração na tarefa de melhor definir o papel do jurista e do Professor de Direito, na sociedade brasileira atual.

Ninguém ignora que o prestígio desta Casa e dos juristas em geral, apresenta-se hoje esmaecido, se o compararmos com o do momento em que seu pai assumiu a cátedra. De nada servirá a lamentação sobre esse estado de coisas, se não nos dispusermos a analisar; com suficiente abertura de espírito, a natureza e a importância das funções que nós outros, juristas e Professores de Direito, temos o dever de exercer no Brasil atual. Ora, essa análise há de partir, necessariamente, de uma reflexão crítica sobre a natureza e a importância desse saber, que somos reputados aplicar e ensinar.

Em que consiste a ciência ou, como preferem alguns, a dogmática jurídica? Qual o seu valor na sociedade atual?

Tais indagações não são de hoje, mas põe-se agora com muito maior insistência e vigor. Já se observou que os momentos históricos de reflexão crítica sobre o valor da ciência jurídica correspondem a épocas de grandes transformaçóes sociais. Quando os pontos tradicionais de referência começam a desaparecer, os homens do Direito sentem-se atacados de compreensivel vertigem e põem em dúvida a importância do seu papel na sociedade.

Essa atitude de espírito, a bem dizer, ainda não se generalizou entre nós. A crítica contemporânea da dogmática jurídica, introduzida no Brasil por alguns poucos pensadores, tem sido obra de reduzido alcance. Mas nem por isso se me afigura um empenho prematuro ou artificial.

Se a ciência jurídica pretende ser uma reflexão sistemática sobre a vida do Direito, é preciso reconhecer que ela tem se limitado, indevidamente, a refletir sobre um só aspecto da vida jurídica: aquela em que aparece o Direito já posto. Cuida-se, assim, de analisar a sua estrutura, a sua função e o modo de aplicá-lo pela operação interpretativa. É nesse campo delimitado que se defrontaram, no século passado, jusnaturalistas e positivistas, e, neste século, remanescentes da chamada «jurisprudência de interesses»; positivistas críticos e adeptos do realismo sociológico. V. Exa., Professor Geraldo Ataliba, sempre marcou sua preferência, nesse debate, pela posição positivista crítica de Hans Kelsen, seguindo, ao que me parece, a linha evolutiva da adesão de seu pai ao normativismo institucional de Santi-Romano.

Ouso dizer, no entanto, que os pensadores do Direito, com raríssimas exceções, têm negligenciado, o estudo, muito mais complexo, do processo criador do Direito na vida social, julgando-o matéria alheia à esfera de competência dos juristas. A ciência jurídica parte 
da ordenação normativa já formada, tida hoje como obra exclusiva do Estado, como antigamente era considerada um produto da natureza. Em ambos os sistemas explicativos, a intervenção do jurista é sempre admitida a posteriori, pelo sábio manejo da técnica interpretativa. Aí, sim, a sua função criadora é hoje reconhecida unanimemente, sendo esse reconhecimento o que diferencia os modernos positivistas críticos dos seus predecessores do século XIX. O problema da criação do Direito, proposto em novas bases por Philipp Heck em sua célebre conferência de 1912, ainda se limita à função inovadora da sentença judicial, ou seja, à interpretaçăo do direito positivo.

Mas se o jurista cria o Direito ao interpretar a norma geral e abstrata da lei, por que não haveria de criá-lo, também, no momento legiferante? Se a lei atual é, sobretudo, uma norma técnica, um instrumento da realização de políticas estatais - e não mais a revelação de princípios imutáveis da natureza ou da razão humana quem haveria de moldá-la com maior competência, senão o técnico em normatividade por excelência?

Que dizer, então, desse vasto trabalho de criação molecular do Direito por meio da formulação de novas técnicas contratuais, numa civilização industrial de massas? Como compreender a geração contínua de novos quadros operacionais, na vida empresarial e administrativa, no plano nacional e internacional, sem o concurso da ars combinatoria dos profissionais do Direito?

E aí, justamente, que se situa, ao que me parece, o campo de eleição para a ciência e a docência do Direito no futuro imediato: - Refletir, sistematicamente, sobre as técnicas de criação jurídica e ensinar a delicadíssima arte do Direito às novas gerações incumbidas de exercê-la. Nessa dupla tarefa, importa estar consciente de que o ordenamento vigente não é somente composto de normas, mas também da teoria jurídica, que lhe dá forma inteligível e aplicável. $\hat{E}$, portanto, um amálgama de normas e de pensamento sistemático. A evolução desse pensamento modifica, até certo ponto, o ordenamento objetivo. É preciso saber, enfim, que a alteração do quadro normativo não se faz em desacordo com as exigências concretas de cada povo, em cada momento histórico; e que no atendimento dessas exigências não se pode deixar de optar entre múltiplos interesses em conflito. $O$ clichê habitual do jurista neutro diante desse universo conflitivo, submisso à vontade objetiva da lei, não passaria de inepta e desprezível imagem, se não servisse como justificativa ideológica para o serviço das dominações do momento. O jurista competente, como V. Exa., que pleiteou e obteve, segundo o modelo paterno, o nobre encargo de ensinar o Direito, deve saber que sua missão não se esgota na simples explicação da ordem vigente, mas consiste, sobretudo, em educar os futuros juristas para o exercício lúcido dessa inevitável opção entre interesses sociais contraditórios, tanto na criação original, quanto na recriação do direito positivo pela via hermenêu- 
tica. Pois na maioria dos casos, os «fins sociais» da lei, a que se refere 0 art. $5^{\circ}$ da Lei de Introdução ao Código Civil, nada mais são do que aquilo que os juristas definem e consagram, como presumida exigência do bem comum.

Se assim é, convém não escamotear o problema da legitimidade da função criadora do jurista, na organização política da nação. Quem lhe conferiu, afinal, tão elevado poder? O nosso Herculano Marcos Inglez de Souza clamava que «a imposição ab alto de regras jurídicas formuladas pelo espírito lógico ou racional dos jurisconsultos titulados ou laureados só se pode equiparar em ilegitimidade e despotismo ao cânon da verdade revelada». O que não o impediu de, em boa consciência, redigir sozinho um anteprojeto de Código Comercial - aliás, excelente para a época - com nada menos que 1.644 artigos.

A rigor, a questão do necessário exercício técnico do poder é um problema geral ligado à burocratização das sociedades modernas; não é um vício específico da atuação do jurista no meio social. Sua solução - ninguém mais ignora - passa pela autêntica democratização da sociedade, com a criação de institutos jurídicos que ensejem mais adequado controle do poder, em todos os níveis: assim, nos órgãos governamentais e nas entidades paraestatais, como nas múltiplas instituições da sociedade civil. E quem haverá de construir esses novos mecanismos de controle, senão o próprio jurista?

Tudo converge, pois, indefectivelmente, para a constituição da vida social. Foi este o campo principal da atividade docente do Professor José Carlos de Ataliba Nogueira e tem sido esta também, se não me engano, a preocupação constante de V. Exa., Senhor Professor Geraldo Ataliba, no terreno do direito público.

A morte impediu seu pai de assistir, agora, a tradição desse mesmo espírito jurídico, de uma geração a outra, na ciência e na docência. Resta-nos, ao menos, o consolo de contarmos aqui, como testemunha superior desta hereditas honorum, a pessoa venerável de sua mãe, a quem rendo, neste momento, todas as minhas homenagens. 